\title{
PROFESSIONAL PRACTICE, AS A STAGE OF FORMATION OF THE FUTURE MODERN SPECIALIST
}

IRMA DIKHAMINJIA

https://doi.org/10.35945/gb.2017.03.021

Doctor of Economics,

Associate Professor of Sokhumi State University, Georgia

KEYWORDS: INNOVATION METHODS OF TEACHING, PROFESSIONAL PRACTICE, CONTEMPORARY WORKFORCE, CO-OP, INTERNSHIP

\section{INTRODUCTION}

With the fast development of technologies, requirements to workforce are constantly changing. Accordingly, requirements of the job market to newly graduates undergo constant transformations. Main goal of the university is to prepare students not only for the existing jobs, but also anticipate expected changes in coming years and adjust teaching philosophy and curricula accordingly. Acquiring new teaching philosophy was not an easy task, in spite of a lot of cooperation with western universities and corresponding trainings. When new teaching methods are introduced which are not gradual transformation of the existing ones, but represent totally different approach, sometimes they deceptively are implemented only formally.One of the main goals of the university is to equip students with the necessary knowledge and skills for their chosen carrier, therefore it is crucial to define necessary skills, to reveal problems in existing teaching methods and structural approaches, and to transform education philosophy of the lecturer accordingly. It is shown how previous teaching methods were adjusted to new challenges and how the role of the lecturer as a central figure of the auditorium changed towards more managerial-like duties. Alongside with the adapted teaching methods, contemporary high education should be enriched with practical experience, that can be best achieved in co-operation with large public organizations and private companies. It should be emphasized that work environment for STEM graduates are among the fastest-changings, therefore the university should not only educate students for current job requirements, but also anticipate expected changes and adjust teaching practices accordingly. By reviewing various literature in this area and considering the authors experience with foreign institutions, the advantages of education enriched with the real-life work experienceis shown. In general, contemporary approaches of education requires to develop general and transfer skills of the students. In addition, by the same approaches, along with the subject knowledge, the student should obtain moral and culture values, ethical decision-making, overcoming stress, communication skills, team-work and emotional intelligence. It means that education should comprise not only a subject knowledge, but also instill conscience. That is the main value which saves the society from the "Machiavellianism" often prevailing in business today.

Today the whole world, not only our society, faces the drastic changes in education field. The whole system of the knowledge is being transformed, and in the states of high technologies, the knowledge is being reorganized and restructured. In our traditional, historically developed system of education (which was established due to being conquered for centuries), there existed a listener (a student) and a lecturer (teacher, professor) in the very sense of these words. In the classroom, in the auditorium, the teacher has a central role, and the listener - passive. The lesson or lecture was noninteractive. Dominant state of the teacher gives bad results on each level of education, due to nonexistent feedback between the lecturer and the student.

Since the managerial activity comprises not only theoretical postulates of management, but its main function is practical implementation of these postulates. Any strategic plan, however well and detailed developed, will stay on paper without proper implementation. Therefore, teaching should be conducted mainly using interactive lectures, business games and case study methods. These approaches will allow to use process of solution of certain problems for gradual learning of theoretical material, which also helps to develop skills and habits for independent working with theoretical information. Supervisor of practical classes should pay attention on the methodology of solution of test problems and cases and usability of these solutions to reallife situations.

Lectures are delivered mainly in view of problem-solving, therefore, to thoroughly understand the lecture content and be an active participant in the discussion, the student has to get to know the literature (at least the reader) given in the syllabus related to the considered topic and to underline crucial postulates and problems to discuss. For the practical coursework it is necessary to read the given literature related to the discussed topic, and to search for other information sources, work with all the searched data, critical analysis of the concepts and statements given on the lecture, and develop one's own position regarding the topic. During seminar it has to be checked how well the student got the materials delivered in the class, or searched independently.

During practical coursework the student should strengthen the obtained knowledge and work out the skills necessary for professional carrier. For this purpose it is important to discuss various problematic case studies defined in the curriculum, also do exercises developed for rational decision-making. Practical work also comprises writing tasks in the form of situation exercises, test questionnaires and colloquium. 
Innovation methods of teaching also means independent work of students. According to curriculum this part requires more time with each consequent level of education: for 6 credit course 85 hours in undergraduate level, 100 hours in graduate studies and so on. Itis defined by the curriculum and represents the time necessary for the successful learning of the course - starting with reading the necessary literature, including group work and preparation for mid-term and final exams. Independent work should help the student to develop interest to the books and other information sources, as well as planning and executive habits, which creates basis for stimulating critical thinking, analysis and conclusion-making skills.

Constantly advancing technologies cause frequent changes in the knowledge and skills requirements of graduates of certain professions, especially STEM scientists and engineers working in high-tech companies or research centers. It is difficult to adjust curriculum and keep up-to-date practice or lab materials at the universities, therefore cooperation of universities with the large high-tech companies or public organizations is invaluable. This kind of practices still is not fully developed in post-soviet countries, but some foreign universities offer vast possibilities to their students, especially on master and $\mathrm{PhD}$ level. The examples discussed in this chapter mainly consider experience of STEM fields, which have one of the fastest changing work environments.

In USA Universities even freshmen students have possibility to spend two months in summer in private companies at paid internship positions where they mainly assist engineers and researchers. This helps them in a lot of aspects, some of them given below: they see in reality what kind of work is available for their profession in future, so they can decide on early stage of education if they are suit well for this work; they gain real-hands knowledge and experience; they learn work ethics, discipline and teamwork in real situations; experience in the area related for their profession greatly helps in getting a good job after graduation. For master and $\mathrm{PhD}$ students there are also cooperation possibilities, so called co-op. In this case the student spends a year or half a year at the company as a junior engineer or scientist, where she is given specific access and tasks. These co-ops usually pay approximately $60 \%$ of the salary the student would have gotten after graduation. Such kind of experience is not only the first major step for further carrier development, but also opens new great possibilities: first of all, the graduate student has access to newest instruments and materials used in the field; the second, the student encounters the most important problems of the field which she can use for further scientific research; the third, the student acquires network of contacts in her professional field and in case of good work can have high-level references to use in future job-searching and the fourth, often students showing themselves as high professionals are invited to work in the same company after graduation.

All these above-mentioned things the undergraduate or graduate level students with internships huge advantage over the students who only pursued academic education or during study worked in the field totally different from their profession. No practical or lab work defined by the university curriculum can give such deep experience or access to contemporary knowledge or requirements, as well planned internship or coop. Therefore, it is important that universities in developing countries offer the same streamlined process for internship and co-op, as it is offered by western universities who developed this practices over several decades. This can be achieved in close collaboration with the large public organizations or private companies, who will also gain significantly.

Since in STEM fields, especially electrical and computer engineering or computer sciences, university curriculum in developing countries are behind by several years, usually companies have difficulties to find suitable applicants for their needs. Survey of the private companies show that usually a company spends substantial human and time resources on specific education of newly hired person. With this kind of collaboration the companies would have opportunities to develop the workforce that would be ready for contemporary requirements, with significantly less expenses.

\section{CONCLUSION}

The described approaches have only indicative character and their usage and form could be changed according to the teaching course and chosen teaching philosophy. Naming the teaching method not always describes exactly what lecturer is delivering in reality. The core of each education approach should be preparation of next generation for the real-life and carrier challenges, therefore the curricullum and work of the teacher can be assessed by how it helps the student to develop professional skills, high work culture and ethics, and independent learning and executive skills.

\section{REFERENCES:}

1. Justin Grandinetti; The Impact of Undergraduate Education on Workplace Writing; James Madison University, 2015;

2. Gelashvili M., Toria P., Themain aspects of teaching business administration in Georgia., Scientific letters of Academic Society of Michael Baludansky., 2017., N5. pp.40-42.

3. Finkelmeyer, Todd. Campus Connection: Are Colleges failing to Prepare Students for the Workplace?, Madison.com. The Cap Times, Nov. 2012. 


\section{PROFESSIONAL PRACTICE, AS A STAGE OF FORMATION OF THE FUTURE MODERN SPECIALIST}

IRMA DIKHAMINJIA

https://doi.org/10.35945/gb.2017.03.021

Doctor of Economics,

Associate Professor of Sokhumi State University, Georgia

KEYWORDS: INNOVATION METHODS OF TEACHING, PROFESSIONAL PRACTICE, CONTEMPORARY WORKFORCE, CO-OP, INTERNSHIP

\section{SUMMARY}

In the present paper we tried to discuss teaching methods and practices for successful preparation of students for contemporary carriers. The paper discusses teaching methods and practices for successful preparation of students for contemporary carriers. With the fast development of technologies, requirements to workforce are constantly changing. One of the main goals of the university is to equip students with the necessary knowledge and skills for their chosen carrier, therefore it is crucial to define necessary skills, to reveal problems in existing teaching methods and structural approaches, and to transform education philosophy of the lecturer accordingly. Paper describes how previous teaching methods were adjusted to new challenges and how the role of the lecturer as a central figure of the auditorium changed towards more managerial-like duties.

The paper also considers the well-established experience practices in foreign universities, considering co-operation and internship possibilities, especially in STEM fields. Work environment for STEM graduates are among the fastest-changings, therefore the university should not only educate students for current job requirements, but also anticipate expected changes and adjust teaching practices accordingly. For this purpose it is necessary that university has constant relation with the possible job market in form co-op and internship. By reviewing various literature in this area and the authors experience, the paper shows the advantages of the students who got real-life practices during their education compared to those who were mostly educated theoretically. 